\title{
Revisión de la Ley para la Inclusión Social y la Garantía de Ingresos: apología de la reflexión
}

\author{
[Jatorrizko hizkuntza: <https://doi.org/10.5569/1134-7147.64.05>]
}

\section{Arantxa Orbegozo Eizagirre}

Dirección de Servicios Sociales, Departamento de Empleo y Políticas Sociales, Gobierno Vasco

<a-orbegozo@euskadi.eus>

Gizarteratzeko eta diru-sarrerak bermatzeko Sistemaren inguruan aldaketa-proposamenak egiten ari dira, izan Legebiltzarrean aurkeztutakoak, izan hainbat entitate eta elkartek landutakoak. Testuinguru horretan, proposamen ofizialaren zenbait alderdi azaltzen dira, batez ere, interesdun guztiek Sistemaren gaineko hausnarketak egiteko eta, horien ondorioz, proposamenak aurkezteko, Legea bera eta dekretuak garatzean. Kontrako iritziak oinarritzat hartzen dira, gaien alderdi gehienak kontuan izateko.

\section{GAKO-HITZAK:}

Diru-sarrerak Bermatzeko Errenta, gizarteprestazioak, eskubide subjektiboak, araudiaren berrikusketa.
Se están planteando propuestas relativas a la modificación del Sistema de Garantía de Ingresos y para la Inclusión Social, tanto en el Parlamento como en otros ámbitos, desarrolladas por determinadas entidades y asociaciones. En ese contexto, se explican algunos aspectos de la propuesta oficial, sobre todo para que todas las personas interesadas puedan aportar sus reflexiones respecto a dicho Sistema y, en consecuencia, puedan hacer aportaciones en el desarrollo tanto de la propia Ley como de sus decretos. Se tienen en cuenta opiniones contrapuestas como base para considerar los variados aspectos de los temas tratados.

\section{Palabras clave:}

Renta de garantía de ingresos, prestaciones sociales, derecho subjetivo, revisión normativa. 


\section{Introito}

En cuestiones de fe, la finalidad del debate no es la búsqueda de asentimiento, sino mostrar al adversario lo incurablemente sordo y ciego que es a 'los hechos' y lo fatalmente adicto que se ha vuelto al prejuicio malicioso. Ese veredicto de malas intenciones hace que resulte superfluo probar la veracidad propia. Se desaconseja encarecidamente escuchar al adversario; sentir empatía por éste es un error fatal, casi suicida.

BAUMAN (2017)

La renta de garantía de ingresos (RGI) hace tiempo que se convirtió en noticia. Si fuera amiga de teorías conspirativas, diría que alguien la había convertido en tal; pero como en ese camino hay demasiadas minas antipersona, será mejor dedicarme a la reflexión, desde el punto de vista más flexible posible. La flexibilidad es imprescindible tanto para eludir las minas como para impulsar el pensamiento. Por eso he utilizado las palabras del difunto señor Bauman como presentación. Hoy en día, en todos los contextos parece que damos más importancia a la ocurrencia puntual que a la verdadera reflexión; además de perder el respeto al arte del bersolarismo, le hacemos flaco favor a nuestro desarrollo personal $\mathrm{y}$, consecuentemente, al desarrollo social.

En general, esa actitud no supone graves consecuencias, aparte de endurecer el tono de las discusiones entre amigos; la misma actitud respecto a los asuntos importantes, sin embargo, enreda los temas hasta el extremo. Y ése es, precisamente, mi mayor temor respecto a las discusiones relativas a la renta de garantía de ingresos, ahora que tenemos el cambio normativo en el horizonte.

Escribo este artículo porque están dándose los primeros pasos de dicho cambio y aún tenemos la oportunidad de dar nuestra opinión. Creo que para garantizar el futuro del Sistema de Garantía de Ingresos y para la Inclusión Social (en adelante, Sistema) son importantes los puntos de vista de todas las personas que tenemos clara la necesidad de estas prestaciones. También agradeceré las opiniones contrarias, pues son útiles para ofrecer nuevos argumentos $y$, por otra parte, porque estar a favor claramente, en ocasiones, limita nuestra visión. No obstante, tanto los puntos de vista favorables como los contrarios son de utilidad siempre que se acompañen de la oportuna argumentación, pues es fundamental argumentar la veracidad de nuestras ideas o, cuando menos, su base.

Antes de continuar debo aclarar que no es mi intención probar los beneficios generales del Sistema -la Iglesia ya tiene sus doctores-, sino ofrecer lo visto y aprendido (lo sospechado, incluso) en el trabajo cotidiano, para que pueda ser aprovechado en otras reflexiones. Compartir es amar, o eso dicen...

${ }^{1}$ En el teatro clásico español, prólogo que explicaba el argumento de la obra y pedía indulgencia al público (RAE dixit).
A modo de índice, pretendo tratar los siguientes asuntos:

- Experiencia de cambio de la gestión de la renta de garantía de ingresos.

- Objetivos del sistema.

- Cuestiones económicas.

- Métodos de acreditación de la residencia efectiva en la Comunidad Autónoma de Euskadi (CAE).

- Relación con el derecho subjetivo a la vivienda.

- Consecuencias para las ayudas de emergencia social.

- Incidencias en la gestión.

- Coordinación, fraude y otros temas delicados.

\section{El presunto fallo original, antes de empezar realmente...}

Desde que la gestión de la RGI cambió de titularidad, en escasas ocasiones se ha tratado la cuestión del cambio en sí. En muchos foros se ha criticado el trabajo de Lanbide -yo misma las he soltado buenas-, pero he escuchado escasas reflexiones respecto al origen de mucho de lo realizado y decidido por Lanbide. Es probable que haya habido más de las que supongo, pero sin salir de determinados ámbitos.

Parece evidente que ahora no tiene ningún sentido sacar la suciedad de debajo de las alfombras, a la búsqueda de culpables; en todo caso, es importante recordar el origen de muchos de los problemas vividos, ahora que está próximo un nuevo cambio. Bajo mi punto de vista, éstos fueron los principales problemas:

- Exceso de confianza -osadía, incluso-a la hora de tomar decisiones.

- Dejar de lado importantes opiniones expertas.

- Ignorar la experiencia práctica de todo tipo de profesionales.

- Tener prisa.

- Cargar sobre personas sin experiencia una responsabilidad excesiva.

A pesar de la gravedad de todo lo anterior, no es original en absoluto; de hecho, tenemos a nuestra disposición una definición al respecto: 'la falacia de la planificación', en los términos utilizados por Tversy y Kahneman para describir los planes y las previsiones que únicamente tienen en cuenta la mejor de las situaciones, sin proponer planteamientos realistas ni considerar lo ocurrido en situaciones similares. Así lo explican:

Las personas a menudo (no siempre) deciden llevar a cabo proyectos arriesgados porque son demasiado optimistas respecto a las 
contingencias que habrán de afrontar

(Kahneman, 2014).

Todo el mundo corre el riesgo de caer en esa mentira, pues no se trata de una capacidad especial de las personas dedicadas a la política, en el pasado 0 actualmente. $Y$ todo el mundo inventa planificaciones pensando que ha tenido en cuenta todos los aspectos y riesgos del asunto. Por desgracia, la realidad escapará, por otra parte, sobre todo si consideramos sospechosas y peligrosas todas las opiniones del resto. Joseba Sarrionandia (1997) viene en nuestra ayuda, ahora que estamos a punto de caer:

Hoy en día la sociedad competitiva hace que la gente ansíe ser 'la mejor'. Resulta lamentable que, quizás, sea ‘la mejor’ sin ser ni tan siquiera 'buena'.

La normativa que tenemos no es la mejor; el proyecto presentado en el Parlamento tampoco lo es; y lo que definitivamente se apruebe tampoco lo será. Lo único que podemos garantizar es que vamos a impulsar un buen proyecto, cada cual desde la responsabilidad que le corresponda o haya interiorizado.

En ese contexto, es imprescindible conocer los pormenores del proyecto presentado. Es probable que algunas de las cuestiones que trate a continuación sean conocidas para determinadas personas; sin embargo, creo que algunas otras interesadas agradecerán alguna explicación, pues en ocasiones no ayudan demasiado los medios de comunicación ni quienes ocupan cargos políticos, ni siquiera quienes trabajamos en este ámbito

El objeto de este artículo es aclarar cuestiones básicas, en la medida de lo posible utilizando ejemplos, para que sepamos de qué estamos hablando en cada momento. Si en mi opinión estas cuestiones están claras (estar de acuerdo sería otra cuestión), no diré gran cosa, por ejemplo, respecto al periodo de empadronamiento o a los abonos indebidos; asimismo, si las personas interesadas están de acuerdo - los aspectos relativos a las personas refugiadas, por ejemplo- no diré nada. Y en la línea señalada al principio, no entraré en encuestas y análisis profundos, pues no es preciso para entender los conceptos básicos. A pesar de lo dicho, en ocasiones las valoraciones serán imprescindibles y, al igual que los ombligos, cada cual tiene la suya, personal (pero dispuesta a transferirse).

Para tal fin, en ocasiones utilizaré como base creencias y opiniones contrapuestas, aunque resulte complicado considerar demasiados asuntos al mismo tiempo. Bajo mi punto de vista, para reflexionar no tiene importancia qué piensa cada cual, a no ser que se trate de una discusión entre personas dedicadas a la política o profesionalmente interesadas en la discusión. A decir verdad, en función de los enredos del día, yo misma soy capaz de creer una cosa y la contraria, una habilidad muy adecuada para ser espía doble... Como decía el señor Bauman (2009), "la persona moral no puede derrotar la ambivalencia, sólo aprender a vivir con ella”.

\section{Curiosa concepción acerca del sistema}

Con el fin de profundidad en esa aparente tibieza, y antes de recibir el castigo anunciado en el Apocalipsis ${ }^{2}$, es preciso considerar que en nuestras discusiones a menudo olvidamos la naturaleza del Sistema, que "tiene carácter subsidiario y, en su caso, complementario" (Decreto 147/2010: artículo 3, apartado 2). En las discusiones relativas a las cuantías, siempre se reivindica la necesidad de aumentarlas, pues las prestaciones actuales no son, ni de lejos, suficientes para que las familias puedan vivir dignamente. Por ejemplo, en la presentación del proyecto en el Parlamento de Vitoria-Gasteiz el pasado mayo, se volvió a señalar que con esas cantidades era imposible que una familia hiciera frente a todos sus gastos.

Los siguientes apartados contienen algunos datos y ejemplos que mostrarán, una vez más, que es imposible pagarlo todo con estas ayudas. Tras repetir la evidencia tres veces, aquí llega la pregunta más complicada de responder: ¿el Sistema debe garantizar que todas las familias dispongan de dinero suficiente para hacer frente a todos los gastos básicos? Conviene andarse con cuidado a la hora de responder (sobre todo, si lo hacemos demasiado deprisa), ya defendamos el Sistema de corazón, o seamos absolutamente contrarios a él, pues es previsible que los grupos se echen en cara mutuamente su demagogia y cinismo, prácticamente antes de acabar de pronunciar la primera frase.

A pesar de ser una crítica rigurosa, tengo clara la necesidad del Sistema, y pienso que este proceso de revisión es muy importante, entre otros motivos, porque se ha hablado demasiado alto en su contra. Quienes lo hacen, en ocasiones, han puesto sobre la mesa problemas reales, pero, en muchas otras, han ofrecido interpretaciones interesadas. Por desgracia, quienes están a favor, en algunos casos, han hecho algo parecido, a modo de contraataque o cualquiera sabe con qué motivo.

En la presente encarnación no espero de quienes están en contra una verdadera reflexión, libre de prejuicios y del ambiente electoral. En el grupo de quienes están a favor, en cambio, agradecería un poco más de prudencia. Damos por sentada la rectitud de quienes combaten la pobreza y la exclusión (acaso por el romanticismo propio de la revolución); pero si tal rectitud no está tan clara, podemos estar ayudando al enemigo.

\footnotetext{
2 "Yo conozco tus obras, que ni eres frío ni caliente. ¡Ojalá fueses frío o caliente! Pero por cuanto eres tibio, y no frío ni caliente, te vomitaré de mi boca" (Ap. 3: 15-16).
} 
Recordando a Susan George (2004), "cuando el adversario intenta intimidarnos con su conocimiento superior, es importante recordar que nuestra interpretación de un determinado conjunto de datos o de una situación es tan buena como la suya". Y para que la interpretación de quienes están a favor sea realmente buena, en mi opinión, aun haciéndola desde un punto de vista crítico, ha de respetar el trabajo realizado en los últimos veintiocho años, incluyendo todos sus claroscuros. Si no se respetan las cosas bien hechas ni a las personas que han trabajado correctamente, porque nuestro único objetivo sea criticar lo que se ha hecho mal y las personas que han tomado malas decisiones, el enemigo está ganando, porque tiene adelantada la mitad del trabajo.

Eso no quiere decir, ni remotamente, que debamos obviar el punto de vista crítico y riguroso a la hora de plantear dudas respecto a las propuestas planteadas, ni que decir tiene, a la hora de plantear propuestas prácticas cada cual desde su propia interpretación. Mucho me temo que es muy sencillo cumplir la primera parte de la frase anterior; interpretar datos y situaciones, tal y como recomendaba la cita previa, es harina de otro costal. Además de ser un trabajo complicado, reflexionar con el fin de solucionar problemas implica cuestionarse los propios puntos de vista, las opiniones y, de vez en cuando, incluso los principios, y no todas las personas son amigas de entrar en esas liosas profundidades.

Para terminar con este apartado, considero que debemos aceptar que el Sistema no puede hacer milagros, y muchas veces parece que le pedimos que se ocupe de todos los problemas de la sociedad, como por ejemplo, cuando reivindicamos que la cuantía de la RGI ha de ser suficiente para vivir dignamente. Para conseguir la susodicha dignidad, seguramente, deberíamos antes arreglar otros problemas. A continuación consta una pequeña lista, provisional e inacabable, para uso de quien tenga interés:

- Pensiones bajas.

- Salario mínimo interprofesional bajo.

- Nóminas bajas.

- Desempleo.

- Trabajos precarios.

- Convenios colectivos injustos.

- Precio de la vivienda.

- Desahucios.

- Escasa oferta de viviendas de protección oficial.

- Precios del gas y la electricidad.

- Favores otorgados a las empresas energéticas para que mantengan los precios en el cielo.

- Dineral regalado a los bancos.

Si nuestro famoso Sistema debe conseguir arreglar los problemas ocasionados por ese embrollo, entonces claramente no tenemos nada que hacer. En este momento, lo que realmente debemos garantizar es que este Sistema de protección tenga futuro, con todos los arreglos y adaptaciones que requiera, de forma que podamos ofrecer ayuda al máximo de personas posible. Dado que no es universal, no me refiero a todas las personas, pues no creo que ese cambio pudiera conseguirse, considerando que en el Parlamento no hay una mayoría suficiente dispuesta a ir por ese camino. Y si el autor de Retrotopía citado al principio no va mal encaminado, cualquiera sabe qué piensa la propia sociedad...

En una sociedad en la que el 'otro' (cualquier otro) es una amenaza, ya sea a cara descubierta, desenmascarada o bien todavía no revelada (y, por esa misma razón, más horripilante y aterradora), la solidaridad (y, en especial, la solidaridad comprometida, pactada y jurada) se le antoja al ingenuo, al incrédulo, al insensato y al frívolo una especie de trampa traicionera (Bauman, 2017).

\section{Cuestiones económicas}

Tal y como señalaba en la presentación, seguiré con algunos asuntos económicos. Tengo claro que no hay muchas personas aficionadas a las matemáticas, pero en nuestra reflexión los números son imprescindibles para entender lo más claramente posible las consecuencias de algunas de las propuestas realizadas.

\subsection{Modificación de la determinación de las unidades de convivencia y de las fórmulas utilizadas para determinar la cuantía básica de la prestación}

Las personas ajenas a los servicios sociales y a Lanbide no tienen muy claro el sentido del concepto 'unidad de convivencia' en el contexto de la normativa del Sistema. Si acaso, se tiene claro que en lugar de haber una persona beneficiaria, es toda la familia quien lo será. No obstante, hemos encontrado abundantes menciones a los nuevos límites que afectarán a las unidades de convivencia (en adelante, UC); básicamente, tanto en los medios de comunicación como en variados foros se ha extendido la idea de que el recorte es la única intención de la propuesta.

Antes de meter la nariz en los resquicios que quedan entre las sospechas y las intenciones, plantearé algunos ejemplos -lo más sencillos posible- para comparar las diferencias entre la situación actual y la que plantea la propuesta, y para explicar el desequilibrio que genera la normativa en vigor; otra cuestión será qué camino se seguirá para equilibrar tal desequilibrio, por arriba, por abajo o en diagonal.

Supongamos que tenemos dos viviendas en el mismo rellano y que todas las personas que allí residen carecen de ingresos: 
A. Viven juntas dos personas sin ningún parentesco entre ellas y cumplen los requisitos para ser consideradas dos UC.

B. Una UC de cuatro miembros, compuesta por una pareja con dos menores.

Hoy en día, en el caso $A$ recibirían dos RGI, una por persona, en la cuantía correspondiente a las UC constituidas por una única persona3: 634,97 $\times 2=$ $1.269,94$ euros. En el caso $B$, por el contrario, les corresponde una única RGI, la propia de las UC de tres o más personas: 901,94 euros.

Hacemos ahora los cálculos basándonos en el contenido de la propuesta, y nos encontramos ante la siguiente situación. En el caso $A$, podrían darse dos supuestos:

- Hasta que se cumpla el plazo que la normativa habrá de aprobar, se considerarán dos UC, igual que hasta el momento: a la primera, le correspondería una prestación de 650 euros; y a la secundaria, 300 euros más; en total, 950 euros.

- Una vez superado ese plazo (12/24 meses, con la opción de ampliarlo si la situación fuera muy complicada), entre los dos cobrarían 750 euros.

La familia $B$ recibiría una $R G I$ de 1.034 euros.

A decir verdad, en este asunto no abunda el gris. Algunos sectores tienen claro que la propuesta es puro recorte. No obstante, a partir de los ejemplos, los recortes se darían, fundamentalmente, en las UC de una única persona que conviven. Cuando las UC están constituidas por más personas, el resultado es superior o bastante parecido durante el tiempo en el que se admite la consideración de una segunda UC en el mismo hogar. Por lo tanto, es precisa una profunda reflexión para establecer en la normativa el límite que la propuesta plantea. ¿Qué quiere decir, exactamente, que "no exista otra alternativa habitacional razonable"? (final del apartado 3.2.1 de la propuesta). Y ya de paso, ¿en qué medida se admitirá prolongar esas situaciones especiales?

A partir de ahí, en caso de desear hacer otro tipo de propuestas, deberíamos escuchar también el resto de opiniones que hay por el mundo, y respecto a este asunto, éstas son el blanco y el negro (o al revés, en función de la opción vital de cada cual):

¡Es un recorte inadmisible!, ¡un máximo de 1.200 euros por vivienda es muy poco!

¡Cómo es posible conseguir tanto dinero en una casa sin trabajar! ¿Dónde tengo que firmar?

Puestas una al lado de la otra, la contradicción es evidente. En nuestro ámbito, la reivindicación de los derechos está muy interiorizada. Sin embargo, las

${ }^{3}$ En todas las cuantías, consta la correspondiente a 2017, incluyendo la minoración del $7 \%$ establecida en la Ley de Presupuestos. personas que no conocen las prestaciones, aunque sean más encendidas en la reivindicación social que las más encendidas revolucionarias de nuestro contexto, en ocasiones no entienden tanto ruido ante la intención de establecer ese límite, sobre todo cuando se trata de personas a las que les cuesta mucho esfuerzo conseguir esa cantidad trabajando; además, en su opinión, no se reivindica en igual proporción la situación de quienes trabajan en las penosas condiciones actuales.

\subsection{Mejorar el sistema de estímulos al empleo}

Antes de empezar, debo decir que, bajo mi punto de vista, la peor medida establecida por el Decreto 147/2010 fue limitar la aplicación del estímulo al empleo, sobre todo desde un punto de vista filosófico. En todo caso, en aquel momento se cumplió lo establecido en el artículo 20 de la Ley 18/2008: "con el fin de reforzar el estímulo al empleo, quedarán excluidos del cómputo determinados porcentajes de ingresos procedentes del trabajo por cuenta propia o ajena correspondiente al solicitante o a otros miembros de su unidad de convivencia. Dicho estímulo tendrá carácter temporal, en los términos que se determinen reglamentariamente, salvo que medie dictamen expreso de los servicios de empleo que recomiende una prórroga”. Por tanto, quienes decidieron marcar un límite estaban cumpliendo lo planteado por quienes aprobaron la Ley.

En este momento, al igual que ocurrirá con algunas otras cuestiones, el acuerdo será total respecto a la necesidad de reforzar los estímulos al empleo. Pero dado que en nuestro mundo los acuerdos son presuntos o aparentes la mayoría de las veces, haré algún comentario respecto a mi cuestión favorita: ¿para qué se establecieron en nuestro Sistema? Tal y como lo explica la propuesta, "busca[n], fundamentalmente, garantizar que todas las personas que ocupan un puesto de trabajo obtengan -a igual situación familiar o de convivencia- unos ingresos totales superiores a aquellos que perciben la prestación y no trabajan, incentivándose así el acceso al empleo". Dicho de otra manera, el objetivo es que quien trabaja disponga de más dinero que quien no lo haga.

Para conseguir ese objetivo, se utiliza una fórmula matemática que se especifica en la Orden de 14 de febrero de 2001. El resultado establece la proporción de los rendimientos de trabajo que no se considerará como ingreso a computar a la hora de analizar la situación económica; por tanto, no se trata de abonar una cuantía especial. Puede que el matiz sea una sutileza, pero creo que podemos aclararlo mediante algún ejemplo. ¡No huyan, amantes de las letras!, pues no explicaré el cálculo, que de eso se encarga la citada Orden.

Imaginemos que una persona que vive sola gana 800 euros al mes, una vez realizadas todas las 
deducciones y prorrateos precisos, para simplificar el ejemplo. Efectuado el cálculo explicado en la Orden, el resultado nos dirá que no computaremos el $44 \%$ de esos ingresos, es decir, 353,10 euros. Así, calcularemos la RGI como si los ingresos reales de esa persona fueran 446,90 euros al mes y, en consecuencia, le corresponderá una RGI de 235,86 euros. En cumplimiento de la Ley de Presupuestos, le aplicamos a esa cuantía un descuento del $7 \%$, y la RGI definitiva será de 219,35 euros al mes. En consecuencia, esa persona dispondrá cada mes de su sueldo y de la RGI resultante: $800+219,35=1.019,35$ euros. Recordemos que una persona sola sin ningún ingreso recibiría una $\mathrm{RGI}$ de 634,97 euros.

Según la normativa vigente, si esas personas viven de alquiler, además les correspondería percibir la prestación complementaria de vivienda (PCV). Por tanto, la situación definitiva sería la siguiente:

- La persona que trabaja, en total, dispondría de $1.019,35+232,50=1.251,85$ euros.

- $Y$ quien no trabaja, de $634,97+232,50=867,47$ euros.

¿Qué ocurre cuando se limita la aplicación del estímulo al empleo, como viene ocurriendo desde $2013^{4}$ ? Quien trabaja, a partir de un determinado momento, pierde el derecho a percibir la RGI y la PCV (no perdería el derecho a las AES, pero dado que esas ayudas están sujetas a presupuesto, no tendría garantizada la cuantía máxima). Por otra parte, quien no trabaja no padecería cambio alguno. Dicho con números: quien trabaja ingresa 800 euros al mes, y quien no lo hace, 867,47 . Una situación verdaderamente adecuada para estimular el empleo.

La segunda intención de ese proyecto es establecer un límite a dicho descuento: se trata de que la cuantía que no se computará deba ser inferior a 400 euros. Si la fórmula se mantuviera, sería muy difícil llegar a ese límite. Por ejemplo, en el caso de una persona sola no ocurriría, pues sería preciso disponer de unos ingresos de 1.269 para que la cuantía a descontar llegara a 400 euros, y en esa situación no le correspondería RGI. En todo caso, aunque la fórmula se ajuste, lo verdaderamente importante es que se mantenga la aplicación del estímulo al empleo y que no sigan dándose situaciones como la descrita.

Para tranquilizar a quienes protegen los presupuestos con denuedo, conviene aclarar que siempre resultará un gasto menor aplicar los estímulos sin limitación temporal. A pesar de que los rumores maliciosos digan que muchas personas quieren vivir del cuento, el deseo de la mayoría es trabajar, entre otros motivos, porque es totalmente diferente conseguir ayuda de la Administración hasta que pasen los malos tiempos que depender de ella

${ }^{4}$ Cuando el Decreto 147/2010 entró en vigor, estableció un plazo de dos años, ampliable otro más. Por tanto, las consecuencias fueron evidentes a partir de 2013. para siempre. El objetivo de la mayoría es, además, conseguir un mínimo de bienestar, no cubrir sin más las necesidades básicas.

Aunque los niveles de desempleo hayan bajado en los últimos tiempos, la mayoría de puestos de trabajo son temporales y de sueldos muy bajos. En consecuencia, debemos prever que habrá más personas trabajando que cumplan los criterios de la RGI. No estarán siempre dentro del Sistema, pero podemos suponer que habrá muchas entradas y salidas. A pesar de todo, dicha situación no debería implicar un incremento directo del presupuesto. Para la Administración, siempre resultará más barato pagar una RGI pequeña -la que se obtiene gracias a la aplicación del estímulo al empleo-que pagar la cuantía máxima. Además, quien permanece en el mundo del empleo siempre tiene más opciones de conseguir algo mejor y, por tanto, mayor probabilidad de dejar de depender del Sistema en algún momento.

El nuevo proyecto ha de superar todo tipo de lecturas y reflexiones: la de quienes defienden el incremento continuo, y la de quienes sostienen que hay que contener el gasto (o 'desean contenerlo', nuevamente, dependiendo de la opción vital de cada cual). Una vez más debemos buscar el equilibrio: si la opción de quienes defienden el incremento constante lograra sus metas, no tengo ni idea de dónde saldría el dinero; si ganasen quienes apuestan por contener el presupuesto al máximo, no sé qué haríamos con toda la gente que se quedaría en la calle. He ido a los extremos intencionadamente, porque en las discusiones tenemos tendencia a posicionarnos de esa manera, como si pretendiéramos organizar un largo asedio. Y no necesitamos nada de eso, es preferible dominar el arte del equilibrismo.

En ese contexto, termino este apartado con una mención a la idea de que este Sistema promueve el trabajo precario. Los contratos temporales y mal pagados están a la orden del día en todas partes, aun cuando existan prestaciones económicas muy bajas -o ninguna en absoluto-. Puede que ciertas personas y entidades se hayan aprovechado de las ayudas del Sistema en su beneficio; a pesar de todo, ese proceder no tiene relación directa con el Sistema, y precisaría de medidas políticas específicas.

\subsection{Cambios en la valoración del patrimonio}

Hemos conseguido casi todo lo que no queríamos. Y es más, ya no queremos casi nada de lo que queríamos.

SARRIONANDIA (1997)

Aunque en Hitzen ondoeza $a^{5}$ este pensamiento se ubique en un momento muy concreto, acertaremos de pleno si lo utilizamos también en el contexto de la valoración del patrimonio. No tengo nada claro cómo y por qué se ideó/propuso/aprobó el primer apartado del artículo 24 del Decreto 147/2010:

${ }_{5}^{5}$ El malestar de las palabras. 
Para acceder a la Renta de Garantía de Ingresos, ni la persona titular ni ningún otro miembro de la unidad de convivencia deberá tener en propiedad ningún bien inmueble, con las salvedades previstas en el apartado b) del párrafo 3 del artículo 9 [vivienda habitual, incluyendo garaje y trastero].

Supongo cuáles fueron los objetivos principales, pero no puedo entender por qué quedó sin matizar límite económico alguno, teniendo en cuenta que la normativa entonces $-\mathrm{y}$ actualmente- vigente especifica claramente un límite general (cuatro veces la RGI que correspondería a la UC si careciera de ingresos).

Como consecuencia de tal decisión, tal y como he repetido estos últimos años hasta cansarme a mí misma, a estos efectos, el Decreto 147/2010 considera de igual manera tener una segunda vivienda elegante en la costa que una caseta de huerta que apenas se tiene en pie. Y como consecuencia de tal consecuencia, demasiadas personas (no puedo decir cuántas, pero con un par ya me parecería demasiado) se han quedado sin ayuda alguna.

Teniendo en cuenta dicha situación, el proyecto recoge las siguientes propuestas:

- Diferenciar el valor y la capacidad de liquidación de los inmuebles, al objeto de no impedir el acceso a la RGI a personas que objetivamente precisan recurrir al Sistema.

- Establecer un sistema de minoración parcial de la prestación vinculado al valor catastral de los bienes en cuestión, considerando un porcentaje de ese valor catastral como renta de la UC y reduciendo, por tanto, en esa proporción la cuantía de la prestación a la que inicialmente se tiene acceso.

- Permitir que en determinados casos el valor considerado para la minoración sea cero, no reduciéndose, por tanto, el importe de la ayuda en tales casos.

Afortunadamente, parece que todo el mundo está de acuerdo respecto a esta cuestión: Lanbide, los servicios sociales de base, el tercer sector, el Parlamento... En todos esos ámbitos se considera que ese apartado ha de corregirse; la duda que me asalta es cómo atinaremos a establecer los requisitos para considerar la "capacidad de liquidación". Si el valor catastral es muy bajo, y conocemos el lugar, en general, las medidas propuestas serán más que suficientes para diferenciar los casos. No obstante, debemos actuar con tiento, para prever las situaciones excepcionales en la medida de lo posible. Utilizar algunos ejemplos, al menos, será de utilidad para poner sobre la mesa determinados tipos de problemas:

- Una familia tiene un bien inmueble en venta hace tiempo. Bajar mucho el precio parece ser la única opción para venderla, pero la familia no quiere perder tanto valor. ¿Hasta qué límite deberían llegar?

- El mismo bien está ubicado fuera de la CAE y, dado que no lo conocemos, no podemos saber hasta qué punto es complicado conseguir su liquidación.

- Una familia que posee una vivienda en propiedad fuera de la CAE y vive aquí en alquiler.

- Poseen una vivienda, pero algún familiar reside en ella.

Si el proyecto mantiene el límite de patrimonio actual, en esos casos las familias no tendrían problemas siempre que el bien no fuera una vivienda $y$, aun siéndolo, si es muy antigua o de escaso valor. Por el contrario, en caso de superarlo, habrá que decidir si en esas circunstancias resulta adecuado que se reciba la RGI.

Por otra parte, teniendo en cuenta que ese tipo de cuestiones eran algunas de las que preocupaban al Parlamento cuando instó a que se modificara el decreto de las AES, conviene aclararlas, pues tienen más importancia de lo que parece. En concreto, la Proposición no de Ley 23/2015, aprobada por el Pleno del Parlamento Vasco en su sesión de 25 de marzo de 2015, señala lo siguiente:
El Parlamento Vasco insta al Gobierno
Vasco a que, teniendo en cuenta tanto sus propios informes como los de las diferentes organizaciones sociales, que ponen de manifiesto nuevas realidades y necesidades no cubiertas que conducen a padecer situaciones de pobreza y exclusión social, dé los pasos necesarios para modificar a lo largo del año 2015 el Decreto $4 / 2011$, con el fin de que puedan acceder a las ayudas de emergencia social las personas que no cuenten con liquidez para atender gastos específicos que prevean o palíen situaciones de exclusión social, así como las nuevas situaciones de pobreza no cubiertas.

Cumplir esa solicitud era imposible mediante la mera modificación del decreto regulador de las AES. Tal afirmación se basa en el hecho de que para la consideración de los ingresos y la valoración del patrimonio, el decreto de las AES nos remite al de la RGI y, por tanto, para cumplir ese mandato, como mínimo, habría sido preciso modificar el decreto de la RGI. De todas formas, tampoco la modificación de los decretos haría milagros si no se cambiara la ley que desarrollan, tal y como se propone en estos momentos.

Si se plantean propuestas para considerar ese tipo de situaciones excepcionales - las recogidas en los ejemplos u otras que podamos conocer-, el equilibrio preciso será muy delicado: por una parte, nuestro objetivo no ha de ser que las personas pierdan todo su patrimonio para poder beneficiarse del Sistema; por otra, debemos asumir que es 
inaceptable que conserven todo su patrimonio, por muy apurada que sea su situación, si éste permite cubrir desahogadamente las necesidades básicas o tiene gran valor, tal y como plantean algunas propuestas.

\subsection{Procedimiento para establecer las cuantías de la renta de garantía de ingresos}

Tarde o temprano percibimos que seguir las reglas, por escrupulosamente que lo hagamos, no nos salva de la responsabilidad. A fin de cuentas, cada uno de nosotros debe decidir cuáles de las reglas en conflicto obedecer y cuáles desechar.

HUXLEY (2009)

La decisión de utilizar el salario mínimo interprofesional (SMI) como base del cálculo de la RGI viene de lejos. La Tabla 1 muestra las cuantías fijadas por el artículo 20 de la Ley $18 / 2008$ en función de las características de las unidades de convivencia (porcentajes del SMI).

Tabla 1. Porcentajes del salario mínimo interprofesional considerados para establecer las cuantías de la renta de garantía de ingresos

\begin{tabular}{|c|c|c|c|c|c|}
\hline \multicolumn{3}{|c|}{ Régimen general } & \multicolumn{3}{c|}{ Pensionistas } \\
\hline $\begin{array}{c}\mathbf{1} \\
\text { persona }\end{array}$ & $\begin{array}{c}\mathbf{2} \\
\text { personas }\end{array}$ & $\begin{array}{c}\text { Más de 2 } \\
\text { personas }\end{array}$ & $\begin{array}{c}\mathbf{1} \\
\text { persona }\end{array}$ & $\begin{array}{c}\mathbf{2} \\
\text { personas }\end{array}$ & $\begin{array}{c}\text { Más de 2 } \\
\text { personas }\end{array}$ \\
\hline $88 \%$ & $113 \%$ & $125 \%$ & $100 \%$ & $125 \%$ & $135 \%$ \\
\hline
\end{tabular}

FUENTE: Elaboración propia a partir de la Ley 18/2008.

Desde la entrada en vigor de esa ley ${ }^{6}$, la evolución del SMI ha sido bastante horizontal: se ha congelado algunos años y, en general, las subidas han sido mínimas. Es evidente que esa situación es negativa para todas las personas que trabajan y, en nuestro contexto, en igual medida, para quienes se benefician de las prestaciones económicas. Desde otro punto de vista, no ha provocado infartos a quienes se ocupan de las responsabilidades presupuestarias en la CAE, pues mantener el cansino ritmo de subida era asumible.

Este año, en cambio, el Parlamento de España aprobó una subida del $8 \%$. Teniendo en cuenta que el SMI del Estado es muy bajo, nos encontrábamos ante un éxito sin precedentes. Aunque, por lo que respecta a quienes se ocupan de nuestro presupuesto, las dimensiones del susto tampoco tenían precedentes. Por el contrario, en los servicios que se ocupan de prestaciones en el resto del Estado no había tal, pues, en general, se utiliza el indicador público de renta de efectos múltiples (Iprem) como referencia para el cálculo de aquéllas, con lo cual la subida del SMI no tenía conexión directa con el presupuesto de nuestro ámbito.

\footnotetext{
${ }^{6}$ En años anteriores, hubo algunas subidas sustanciales que supusieron incrementos importantes de las prestaciones. No obstante, el contexto económico general era totalmente diferente al actual.
}

Tras las dudas, reflexiones y las consecuentes discusiones, como es bien sabido, el Gobierno Vasco decidió utilizar la subida del índice de precios al consumo para establecer la cuantía de la RGI, y así quedó recogido en la disposición adicional $7^{\underline{a}}$ de la Ley 2/2017, por la que se aprueban los Presupuestos Generales de la Comunidad Autónoma de Euskadi para el ejercicio 2017:

Durante el ejercicio 2017, la cuantía de la renta de garantía de ingresos, en cualquiera de sus modalidades, así como del subsidio mensual complementario para unidades de convivencia monoparentales, será la aplicada durante el ejercicio 2016, incrementada en el porcentaje del $1,5 \%$.

Al principio de este apartado he aprovechado una cita de La isla de Aldous Huxley, obra en la que en muchas ocasiones nos dicen "jatención!, jahora y aquí!”, pues en esa isla le dan extraordinaria importancia a lo que estamos haciendo en cada momento. En nuestra vida cotidiana, en cambio, generalmente estamos recordando e interpretando el pasado (acaso intentando arreglar algo) o imaginando y organizando el futuro.

Ahora y aquí carece de sentido enredarnos en los motivos que ocasionaron que el Gobierno Vasco tomara esa decisión 7 , aunque también creo que precisan alguna reflexión. Puestos sobre la balanza, quienes ocupan un extremo aseguran que se trata de una maldad ilegal e imperdonable; en el otro extremo, tenemos a quienes defienden la decisión, desde variados puntos de vista prácticos. Como vivo buscando el equilibrio, este asunto me deja las piernas temblorosas: a pesar de entender todos los argumentos, considero que no era factible hacer frente de repente a una subida semejante sin organizar un hermoso estropicio en el resto de servicios del Departamento, mejor dicho, en los servicios de todos los departamentos.

La revisión de la Ley supone un contexto inmejorable para hacer propuestas: límites de las cuantías, procedimientos de cálculo, índices adecuados... No obstante, conviene andarse con cuidado a la hora de plantear propuestas, sobre todo porque las consecuencias imprevistas tienden a aparecer por doquier.

Por lo que respecta a las cuantías, tal y como estamos viendo, el incremento es la reivindicación básica. Supongamos ahora que el primer sector de nuestra balanza gana las próximas elecciones y decide aplicar una subida del $20 \%$. Para hacer frente al gasto, deciden subir los impuestos, en las proporciones adecuadas para que quienes

7 Debemos tener en cuenta, además, la disposición transitoria $2^{\text {a }}$ del Real Decreto $742 / 2016$, por el que se fija el SMI para 2017. Facilita que los Gobiernos de las comunidades autónomas no apliquen la subida, dando cobertura jurídica a esa decisión, aunque es discutible que eso fuera aplicable en nuestro caso. 
más tienen paguen mucho más que hasta ahora. En cuanto al salario mínimo, no pueden hacer gran cosa, por depender del Estado, así que optan por establecer un salario mínimo vasco, para que nuestras empresas paguen como se debe.

A pesar de vivir en una isla especial, vuelven a celebrarse elecciones y, ¡oh, sorpresa!, ahora gana el sector del otro extremo de la balanza, contrario al Sistema, gracias a su promesa de bajar los impuestos. 0 ganan otra vez los primeros, pero piensan que es preciso utilizar las tijeras, tal y como vemos en nuestra realidad desde 2012 hasta el presente, ejercicios en los que la Ley de Presupuestos ha hecho su labor de ajuste ${ }^{8}$.

En algunos ámbitos se antoja imprescindible garantizar algún procedimiento que imposibilite que las cuantías puedan modificarse según los deseos de los partidos políticos, o al gusto de la mayoría parlamentaria. Bajo mi punto de vista, eso es imposible, pues las leyes, de la misma manera que se aprueban, se pueden derogar, y tenemos ejemplos disponibles de sobra. La diferencia proviene de las proporciones que cada opinión ocupe en el Parlamento: en caso de mayoría absoluta, quienes la consigan harán lo que deseen (a no ser que tengan otras necesidades en otras instituciones), y quien precise acuerdos, los buscará, si es preciso, incluso, entre amistades sospechosas.

Teniendo en cuenta todo lo anterior, no veo nada claro qué beneficio aporta utilizar un índice fijo, por muy fiable que resulte. Como ejemplo podemos utilizar el propio Iprem, que se instauró, sobre el papel, con el argumento de que facilitaba a las familias en peor situación su acceso a las prestaciones. No se señalaba, en cambio, cómo afecta el mismo índice cuando se utiliza para establecer la cuantía de dichas ayudas.

Está bien poner al Gobierno en apuros respecto a este asunto. En todo caso, si gracias a esa presión se consigue establecer algún índice al gusto de determinados sectores, tal éxito no garantizará, en absoluto, la cuantía de la RGI de aquí en adelante.

No sé cuál sería la cuantía correcta. Alcanzo a entender el origen de las propuestas presentadas y los motivos de plantearlas. Si quienes proponen establecer cuantías mayores especifican cómo conseguirán el presupuesto necesario, estoy lista para reflexionar al respecto, con todas mis limitaciones. Si la base de sus explicaciones

${ }^{8}$ Ley 2/2017, disposición adicional sexta:

1. Las ayudas, subvenciones y prestaciones económicas, salvo las establecidas en la presente ley, que, al amparo de la regulación recogida en disposiciones de carácter general, se concedan, reconozcan o paguen por las entidades del sector público en el ejercicio 2017 sin necesidad de efectuar previa convocatoria pública ni precisar, a los efectos de fijar el límite de gasto, de publicidad previa de los recursos presupuestarios vinculados a su financiación, experimentarán una reducción en su cuantía del $7 \%$. implica un cambio general y profundo en el ámbito económico, mi pregunta inmediata sería qué hacer mientras tanto, hasta conseguir realmente los presupuestos que se planteen lograr.

\section{Acreditación de la residencia efectiva en la Comunidad Autónoma de Euskadi}

Según la normativa, es imprescindible que las personas estén empadronadas y residan efectivamente en la CAE (artículo 16 de la Ley 18/2008). A pesar de su aspecto de matiz insignificante, este asunto tiene particular importancia en determinados casos.

Acreditar que una persona está empadronada es muy sencillo; sin embargo, acreditar que realmente vive donde dice vivir implica mayores dificultades. Por una parte, la normativa no aporta criterios específicos para establecer un procedimiento al respecto; por otra, y por variados motivos, los ayuntamientos - en la mayoría de casos - no hacen un seguimiento a las personas empadronadas. Ante tal situación, el proyecto presenta varias propuestas, teniendo en cuenta el máximo de opciones posibles para acreditar que las personas residen donde están empadronadas:

- Informes de arraigo, que han de elaborar los servicios sociales de base o los servicios competentes del Gobierno Vasco.

- Certificados laborales.

- Inscripción en Lanbide como solicitante de empleo.

- En caso de convivir con menores, certificados de escolaridad.

- Contratos de alquiler.

- Justificante de uso de suministros para la vivienda.

En muchos casos basta con el empadronamiento, porque alguna Administración tiene relación directa con las personas, y gracias a alguna de las opciones planteadas, será sencillo acreditar también la residencia efectiva. Pero en determinados casos surgen las sospechas, sobre todo cuando Lanbide recibe de vuelta notificaciones imposibles de aceptar, porque la persona titular no se encontraba en la dirección facilitada. Es evidente que en muchos casos esa circunstancia se debe a que las personas se han trasladado de un domicilio a otro - en la propia CAE, o en el mismo municipio, incluso- sin modificar el padrón y sin dar cuenta a Lanbide.

Uno de los requisitos básicos que han de cumplir las personas beneficiarias es comunicar cualquier cambio que pueda afectar a la RGI; por tanto, aunque no exista ninguna intención maliciosa, estos casos no respetan la normativa y, lo que es peor, extienden el tufillo de la sospecha, sobre todo cuando los medios de comunicación nos ofrecen diligentemente 
los porcentajes de notificaciones que volvieron sin cumplir su cometido. Así, los rumores relativos al fraude se oyen cada vez más altos y lo anecdótico se transforma en Verdad revelada.

Por otro lado, la mentira no se esconde tras todas las sospechas, y es innegable que existen casos de fraude evidentes, por mucho que haya dudas respecto al porcentaje que representan. En ese contexto, tiene mucha más importancia de la que parece el hecho de acreditar la residencia efectiva $y$, a tal fin, es imprescindible que la normativa ofrezca vías para conseguirlo; de lo contrario, siempre estaremos ideando procedimientos provisionales.

Partiendo de la propuesta, es importante fortalecer las relaciones entre administraciones, con la clara intención de evitar el máximo posible de trámites burocráticos. Lanbide dispone de información cuando en la UC alguien ha solicitado trabajo, o si antes lo ha desempeñado. Por lo que respecta a los servicios sociales de base, el mejor ejemplo sería la gestión de las AES, pues gracias a ese trabajo, en muchos casos, la Administración ya dispone de facturas, contratos de alquiler...; por otra parte, también tienen relación con servicios ajenos, entre otros, con las escuelas y los servicios sanitarios.

Todo lo anterior guarda relación directa con la necesidad de coordinación, pero este asunto precisa de un apartado propio. Más adelante algo veremos al respecto, junto con otra serie de temas complicados.

\section{Relación con el derecho subjetivo a la vivienda}

Conocía la historia. Pero no la verdad. FUENTES (cit. en Uribe, 2016)

Con esa frase de Carlos Fuentes inicia Kirmen Uribe (2016) su última novela, y también la quiero aprovechar, porque respecto a este asunto me han llegado ideas cambiantes.

La exposición de motivos de la Ley $18 / 2008$ estableció la provisionalidad de la prestación complementaria de vivienda (PCV), la cual "sólo permanecerá integrada en el Sistema Vasco de Garantía de Ingresos e Inclusión Social en tanto no se articulen, en el marco de la política pública de vivienda, medidas análogas o de otra naturaleza que den cobertura a la misma necesidad de acceso a la vivienda de los colectivos más vulnerables y desfavorecidos". Y ese momento está más próximo gracias a la aprobación de la Ley 3/2015, de Vivienda.

La pasada legislatura terminó sin culminar el "proyecto de decreto relativo al derecho subjetivo a la ocupación legal de una vivienda digna y adecuada". En estos momentos (julio de 2017), se está trabajando en un nuevo proyecto. En el portal de Transparencia de Euskadi.eus tenemos a nuestra disposición la Orden de Inicios.

En este contexto, conviene recordar la primera característica del derecho establecido en la Ley $3 / 2015$, de Vivienda, señalada en su noveno artículo:

1. La satisfacción del derecho a la ocupación legal de una vivienda digna y adecuada podrá ser realizada por parte de las administraciones públicas vascas con competencia para ello mediante la puesta a disposición, en régimen de alquiler, de una vivienda protegida o de un alojamiento protegido, o incluso de una vivienda libre en caso de su disponibilidad por causa de programas de intermediación u otros, con la renta o el canon que corresponda en cada caso.

2. En defecto de vivienda o alojamiento, y con carácter subsidiario, esta satisfacción podrá efectuarse mediante el establecimiento de un sistema de prestaciones económicas.

Aunque el citado artículo establece los requisitos generales para acceder al derecho subjetivo a la vivienda, la Ley debe desarrollarse mediante el oportuno decreto. Por otra parte, el Gobierno ha aceptado dos proposiciones no de ley relativas a este proyecto: el 9 de febrero de 2017 aceptó la número 12/2007, y el 14 de abril de 2016, la número 32/2016. Las citadas proposiciones no de ley han tenido presentes determinadas cuestiones cuyo objetivo es que no se limiten los derechos actuales. Por ejemplo, la de 2017 solicita lo siguiente:

\section{El Parlamento Vasco insta al Gobierno Vasco a garantizar que el desarrollo del decreto regulador del derecho subjetivo de acceso a una vivienda digna no suponga ningún recorte, ni en requisitos ni en cuantías, en los derechos reconocidos hasta el presente.}

Así garantizamos que quien actualmente tiene derecho a percibir la PCV no sufrirá pérdida alguna si a partir de determinado momento comienza a recibir la nueva prestación; sin embargo, no queda clara la intención respecto a quienes soliciten la prestación una vez aprobado el decreto.

La proposición de 2016 recogía un contenido similar. Añadido a lo anterior, y a pesar de considerar determinados aspectos, entiendo que dejaba demasiadas cuestiones en el tintero, sobre todo relativas a los requisitos. Sabemos que en estos momentos se está desarrollando otro proyecto, con su propio camino por delante, por lo que habrá oportunidades de participación. En todo caso, es probable que los matices que faltan sean de interés en cuanto al mantenimiento del nivel de derechos; por tanto, únicamente subrayaré los más relevantes.

9 〈http://www.legegunea.euskadi.eus/x59-contfich/es/contenidos/tramita_decreto/dncg_dec_135117_17_05/es_def/index.shtml〉. 
a. Antigüedad en el Registro de Solicitantes de Vivienda Protegida y Alojamientos Dotacionales

La disposición transitoria $4^{\text {a }}$ de la Ley $3 / 2015$ estableció como requisito, entre otros, un mínimo de cuatro años como solicitante de vivienda en alquiler para la satisfacción del derecho subjetivo de manera provisional, "hasta tanto no se publiquen las disposiciones reglamentarias previstas en el artículo 9 de la presente ley, referido a los modos de satisfacción y requisitos de exigencia del derecho subjetivo a la ocupación legal de una vivienda digna y adecuada".

La Proposición no de Ley 32/2016, por su parte, solicitaba que dicho plazo bajara a los tres años, "en tanto no se publiquen las disposiciones reglamentarias previstas en el artículo 9 de la Ley $3 / 2015$ ". Vista dicha solicitud, no podemos tener clara la intención real: tomar una decisión provisional hasta plantear el resto de reflexiones posibles, o adelantar el contenido del decreto que habrá de desarrollarse.

En todo caso, considero que no se ha tenido presente la consecuencia directa de esa decisión, ya se trate de un límite de tres o cuatro años. Por lo que respecta a esta cuestión, los requisitos vigentes en el Sistema son los siguientes:

- Antigüedad en el padrón: tres años para la RGI y la PCV, y seis meses para las AES.

- Constar como solicitante de vivienda en el servicio de Etxebide, o haber solicitado la inscripción.

La Ley 3/2015 no establece límites respecto al padrón. Vista desde fuera, tal circunstancia parece implicar una flexibilización en el derecho. El límite de tiempo como solicitante de alquiler registrado, por el contrario, endurece las condiciones de acceso, pues para constar en el registro de Etxebide es preciso cumplir requisitos específicos, y algunos son más difíciles de cumplir que los establecidos como acceso al Sistema, en particular, los relativos a los siguientes aspectos: es preciso contar con el permiso de residencia, y existe un mínimo de ingresos (al cual nos referiremos en el siguiente apartado).

Por otra parte, es preciso aclarar un matiz añadido: el proyecto anterior planteaba el cálculo de los cuatro años de antigüedad desde la última inscripción; de ahí que, caso de que la persona hubiera tenido varias entradas y salidas en el registro, se tendría en cuenta la última entrada como inicio del cómputo del plazo. Como consecuencia, el plazo teóricamente establecido - sean tres o cuatro años- podría alargarse sin límite.

También debemos tener presente que algunas personas jamás han solicitado constar en el registro. Cada caso se deberá a un motivo diferente: en ocasiones, se considera que carece de sentido, dada la escasa oferta; otras nunca han conocido empleos que no fueran provisionales; $y$ otro grupo no es consciente de las implicaciones que tal registro puede tener para conseguir otro tipo de beneficios. Podemos encontrar todo tipo de supuestos.

La diferencia es sustancial si tenemos en cuenta que el requisito general en el Sistema era estar inscrito o haberlo solicitado. De ahí que adquiera particular importancia aclarar qué pretende exactamente la proposición no de ley presentada en el Parlamento: que el nuevo decreto no establezca restricciones respecto a los derechos actualmente reconocidos - ni en cuanto a requisitos ni respecto a las cuantías-, con el fin de garantizar los derechos de las personas actualmente beneficiarias, o garantizar el mismo nivel de derechos para las personas que puedan precisarlos en el futuro.

\section{b. Requisitos económicos}

El quinto apartado de la proposición no de ley de 2016 instaba al Gobierno Vasco “a que en ningún caso los requisitos sobre la renta exigibles a los beneficiarios del derecho subjetivo a una vivienda digna puedan ser superiores a los señalados en la Ley de Garantía de Ingresos y para la Inclusión Social para la obtención de la RGI”.

Por lo que respecta a la situación económica, en la gestión de la RGI no existe mínimo, pues se acepta que las personas no dispongan de ingreso alguno. Sin embargo, para constar en el registro de Etxebide está vigente un límite de 3.000 euros respecto a la última declaración fiscal. Por muy pequeño que sea, puede suponer un obstáculo insalvable, sobre todo si se amplía el límite temporal tratado en el anterior apartado.

Se trata, además, de un requisito que afectará a todas las personas solicitantes, en particular a quienes tienen empleos provisionales, más aún, si perciben sueldos pequeños. Es probable que ocasionalmente consigan constar en el registro, pero caso de perder su empleo, las revisiones de Etxebide podrían dejarlas fuera y, consecuentemente, el citado cálculo se iniciaría de cero una vez más.

\section{c. Situación de las personas inmigrantes}

Para constar en el registro es suficiente el permiso de residencia temporal. Sin embargo, el Sistema de Garantía de Ingresos admite las solicitudes de las personas inmigrantes aun cuando carezcan de tal permiso, con lo cual quienes se encuentren en tal circunstancia no podrían constar en el registro $y$, en consecuencia, el plazo antes señalado se podría volver a prolongar mucho más allá de lo previsible. 
Podemos comprobar, una vez más, que los matices son realmente importantes. Si el decreto regulador del derecho subjetivo a la vivienda deja a actuales personas beneficiarias de la PCV sin acceso a una prestación similar, las AES serán la única oportunidad de conseguir alguna prestación para el alquiler, con lo cual adquirirán mayor importancia, dado su "carácter subsidiario y, en su caso, complementario de todo tipo de recursos y prestaciones sociales de contenido económico previstos en la legislación vigente" (Decreto 4/2011: artículo 4).

Resulta evidente, considerando todo lo señalado hasta el momento, que el hecho de que un derecho sea subjetivo, en sí mismo, no supone necesariamente un mayor beneficio. Es frecuente la reivindicación de los derechos como si tal subjetividad fuera sinónimo de universalidad; aunque parezca obvia la diferencia, dichas reivindicaciones en escasas ocasiones profundizan en matizaciones tan escabrosas.

En nuestro caso, además, estamos hablando de dos derechos subjetivos $\mathrm{y}$, a pesar de que cada uno tenga contenido propio, la relación entre ambos es muy estrecha. Hace algún tiempo, algunas personas con responsabilidades políticas relevantes auguraban una situación futura con una suerte de ventanilla única; lo que estamos viendo, por el contrario, es que hemos conseguido un hermoso mirador.

Es probable que debido a lo complicado de la conexión entre sistemas, obviada la importancia de los matices, tanto la mayoría de las partes interesadas como el propio Parlamento hayan dado mayor importancia a los objetivos elevados. Por eso, es fundamental repetir una y otra vez que resulta imprescindible reflexionar respecto a la relación entre administraciones, para que el Sistema no se quede cojeando. Así, es preciso que la revisión del Sistema tome en consideración el nuevo decreto de Vivienda, porque el nuevo derecho subjetivo a la vivienda incide directamente en la situación de las personas beneficiarias de PCV y AES.

Podemos discutir hasta el infinito para establecer el límite de ingresos mínimos para vivir dignamente; pero si se discute por parcelas, es decir, cuánto hace falta para comer, cuánto para pagar el alquiler, para el gas y la luz, cuánto para..., perderemos el norte y el resto de los puntos cardinales. Tristemente, la mayoría de discusiones en el ámbito político suelen ser de esas características, al menos las que se producen cuando los medios de comunicación o algún tipo de público agradecido está presente.

En consecuencia -o porque así se desealos medios de comunicación (salvo honrosas excepciones), en lugar de ofrecer información veraz $y$ reflexiones al respecto, nos presentan temas puntuales como si fueran noticia, desde el punto de vista de cada medio: quienes defienden (en teoría, al menos) los derechos de las personas en situación de pobreza, para denunciar los errores o la escasa formalidad del Sistema; o por el contrario, quienes están dispuestos a denunciar los supuestos fraudes de dichas personas -o su vagancia-, poniendo datos indiscutibles sobre la mesa. Y así no hay manera de arreglar nada en absoluto.

\section{Consecuencias para las ayudas de emergencia social: algunas ideas}

Las ayudas de emergencia social (AES), como la mayoría de hermanas pequeñas (servidora incluida), dan bastante más trabajo del que parece.

Si las conexiones entre sistemas no se organizan debidamente, es probable que la consecuencia directa de este proceso sea que, para algunas/ muchas personas (en función de la versión definitiva de la normativa), las AES sean la única opción de conseguir una prestación para pagar el alquiler. Como ya se ha intentado explicar en el apartado anterior, eso ocurrirá si las partes implicadas no son cuidadosas a la hora de organizar la relación de la PCV con la prestación del nuevo derecho subjetivo a la vivienda.

Hace muchas palabras, cuando he mencionado la Proposición no de Ley 23/2015, supongo que ha quedado bastante claro que, en general, los temas se lían demasiado, seguramente, porque son liosos en sí; y lo son tanto como las mentalidades, y tanto entre las personas en general como entre quienes ocupan los asientos del Parlamento. Y entre todos los líos, el lío más lioso es la propia naturaleza de las AES.

El origen está en su propia denominación: las ayudas de emergencia social se crearon para ofrecer prestaciones puntuales en momentos de emergencia (perdón por la perogrullada), hasta que la situación familiar volviera a su ser. A pesar de tal denominación, es evidente que la situación de emergencia de algunas personas es permanente 0 , cuando menos, que siempre se cumplen los criterios como para que su situación sea considerada como tal emergencia. En consecuencia, algunas personas quedarán para siempre al amparo de estas ayudas.

¿Qué supone eso? ¿Debemos reconsiderar la intención inicial? ¿Debemos dejar los requisitos tal y como están? ¿Debemos flexibilizarlos para hacer frente a las "nuevas situaciones de pobreza", tal y como nos instaba el Parlamento? ¿Endurecerlas, pues nuestra generosidad carece de sentido ante el tufillo a fraude que pulula por doquier? Conste que el propio Parlamento tiene muchas firmas que defienden esta última postura...

Tras hacer referencia a tantos embrollos, he pensado que algunas personas, osadas lectoras ellas, no sabrán para qué son las famosas AES. Se utilizan para hacer frente a los gastos generales del hogar; resumiendo, para los siguientes tipos de gasto: alquiler, crédito para la adquisición de vivienda, 
gastos de energía (lo cual no es ninguna novedad, por mucho que ahora conste con nombre propio en la normativa, pues desde siempre se han dado prestaciones para esto), mantenimiento y arreglos de la vivienda, gastos que la Administración no garantiza (dentista, gafas) y endeudamiento.

La normativa reguladora de las AES tiene una característica importante: considerando que, en general, no es posible conceder las prestaciones previstas a todas las personas que cumplen los requisitos, el propio decreto obliga a los ayuntamientos a restringir las AES, de forma que el mayor número posible de familias se beneficien de aquéllas. De todas formas, no especifica cómo ha de realizarse tal minoración; aunque señale un cálculo basado en porcentajes, permite que se utilicen otros procedimientos de minoración. Tal circunstancia supone que las diferencias entre municipios sean sustanciales:

- Algunos minoran determinados porcentajes, en función del tipo de concepto de que se trate. Por ejemplo, en las AES por alquiler se resta un $20 \%$ al resultado obtenido aplicada la normativa, y en el mantenimiento de la vivienda, una minoración del $25 \%$.

- Otros optan por una base similar a la del ejemplo anterior, pero estableciendo algunas excepciones; en su caso, podrían decidir no minorar a las personas que perciban pensiones mínimas.

- Otra opción sería limitar el número de conceptos. Podría decidirse conceder AES que correspondan únicamente a dos tipos de gasto -alquiler y energía, en su caso- o un solo concepto, incluso.

- Por último, algunas entidades optan por no hacer minoración alguna y, una vez agotado el presupuesto, las AES quedan en suspenso hasta el siguiente ejercicio.

Además, algunos ayuntamientos deciden añadir presupuesto propio a la cuantía asignada por el Gobierno Vasco y, gracias a ese incremento, hacen minoraciones inferiores o, en algunos casos, ninguna en absoluto. Tal opción supone que partir de la misma normativa no garantice que se vaya a percibir la misma cuantía en todos los municipios, pues el propio Decreto abrió la vía para que tales diferencias se produjeran. Es más que probable que la intención original fuera respetar el conocimiento que los municipios poseen respecto a su situación, pues los servicios sociales de cada pueblo conocen con detalle la situación general y los pormenores de los casos. A pesar de todo, superar tal consecuencia será realmente complicado.

El único camino que me planteo es que sea el propio Gobierno Vasco quien establezca los tipos de minoración posibles, pero tal decisión no lo arreglaría todo, pues compete a las entidades decidir si añaden presupuesto propio y, como se ha visto, tal decisión incide directamente en las AES que definitivamente se conceden.
Por otra parte, debemos considerar que los datos que se utilizan para establecer las asignaciones son los mismos para todas las entidades. Desde el ejercicio 2014 hasta el presente, se han utilizado dos: el número de RGI y el número de personas que no perciben prestación alguna.

Antes se utilizaba un mayor número de criterios, con la intención de ajustar el cálculo. En todo caso, los criterios anteriores suponían una consecuencia peculiar, pues algunas personas se tenían en cuenta en más de una ocasión. Utilicemos como ejemplo una mujer inmigrante desempleada: se tenía en cuenta en tres ocasiones, con distinto peso en función del criterio que estuviéramos analizando. Obviamente, esa persona percibirá lo que a ella le corresponde, pues no se le concederá dicha ayuda triplicada. Siendo así, ¿por qué computarla tres veces?

Creo que las reflexiones relativas a los criterios de cálculo de las asignaciones brillan por su ausencia, que yo sepa, al menos. Sean buenos o malos, no se reciben propuestas al respecto, por mucho que, cuando se decidió cambiarlos, el Departamento formalmente se comprometiera a analizar cuantas propuestas se recibieran. Y no tengo más que sospechas al respecto: se aceptan las actuales porque afectan a todos los municipios por igual; no hay demasiada idea novedosa; se presupone que el Departamento no hará mucho caso... Por lo que respecta a esa última, en su día se rechazaron algunas propuestas, porque supondrían beneficiar a determinados ayuntamientos o porque suponían volver a considerar más de una vez a algunas personas, tal y como venía ocurriendo.

Por el contrario, son frecuentes las voces que reivindican que las $A E S$ se conviertan en un derecho subjetivo. A pesar de ser propuestas bienintencionadas, bajo mi punto de vista no tienen en cuenta ni las características de las AES ni su importancia en el conjunto del Sistema. Tal y como Susan George señalaba en la obra antes citada (2004), "una de las mejores formas de perder una batalla es basar las estrategias en premisas falsas y en ilusiones".

Creo que en estos momentos conseguir que las $A E S$ se constituyan en derecho subjetivo no ha de ser el objetivo principal. Tal opinión no implica que quien tenga clara la contraria deba olvidarla, sino que convendría que tuviera preparadas otras propuestas para presentarlas al mismo tiempo. Si la revolución absoluta es la única intención, se perderán oportunidades para conseguir avances menores. Una vez más, debemos recordar las actitudes y opiniones del Parlamento actual (y su próxima composición, seguramente, será bastante parecida) -y de la sociedad-, para no pensar que el futuro nos deparará cambios asombrosos.

Por lo que respecta a las AES, en estos momentos el objetivo fundamental ha de ser que los requisitos para acceder al derecho subjetivo a la vivienda no 
endurezcan los de la RGI (y, en consecuencia, los de la PCV). Si eso se consigue, los ayuntamientos no deberán asumir la responsabilidad de parte de las prestaciones que hoy en día gestiona Lanbide.

Por otra parte, muchas de las prestaciones por alquiler que hoy en día gestionan los ayuntamientos pasarían a ser competencia de Etxebide. Antes de ponernos a aplaudir, debemos recordar que cuando la PCV entró en vigor, el presupuesto de AES menguó, en la proporción prevista para abonar la PCV a las personas beneficiarias de RGI.

Si tenemos en cuenta todo lo anterior, caso de que el presupuesto general no se incremente, lo que realmente estaremos haciendo será pasar partidas presupuestarias de un servicio a otro. Espero que disculpen la repetición de obviedades, pues en ocasiones no tenemos en cuenta las cuestiones más evidentes. Por lo tanto, los ayuntamientos no dispondrán de repente de una asignación superior para hacer frente al resto de gastos. En ese sentido, y si las características básicas del Sistema no cambian, será preciso mantener los citados criterios para fijar prioridades, salvo en el supuesto de que la propia Ley establezca criterios prácticos más específicos (o la necesidad de establecerlos reglamentariamente), cuando menos para disminuir las diferencias entre municipios.

En ese sentido, la compensación establecida por la Ley $2 / 2016$, de Instituciones Locales de Euskadi, no garantiza que en el futuro se proceda de igual manera, pues la disposición transitoria octava ha señalado expresamente que tal compensación se mantendrá hasta que la nueva normativa se revise. Grosso modo, sin agotar al mundo con demasiadas cifras, la cuantía máxima que se compensaría sería el $30 \%{ }^{10}$ de la asignación total; en todo caso, la compensación correspondiente al ejercicio 2016 se ha quedado en la mitad. Está por ver qué ocurrirá el próximo ejercicio.

Teniendo en cuenta los derroteros por los que avanzan las propuestas de revisión del Sistema, agradecería vivamente que las personas profesionales de los servicios sociales de base presentaran oficialmente sus opiniones y reflexiones, pues lo ocurrido en los últimos años es fundamental para considerar las consecuencias de las propuestas, para bien o para mal. Como ejemplo podemos señalar que quienes pierden la RGI -o la mayoría de personas que no cumplen los criterios de accesoacuden a dichos servicios municipales en busca de alguna ayuda; por tanto, conocen con detalle las vicisitudes de los casos más graves. De igual manera, el punto de vista de muchas profesionales que trabajan en nuestro ámbito para entidades del tercer sector también será interesante, pues quienes no cumplen los requisitos de la normativa $-y$, según

${ }^{10}$ Teniendo en cuenta que la asignación total para 2016 ascendió a 23.000 .000 , el citado $30 \%$, es decir, el máximo a compensar, supondría 6.900 .000 euros. los casos, también quienes los cumplen - reciben el apoyo de dichas entidades.

El primer paso será revisar la Ley y, derivada de tal revisión, habrán de elaborarse los decretos que la desarrollarán. La Ley establecerá las líneas maestras, pero corresponderá a los decretos profundizar hasta establecer todos los detalles relativos a los requisitos y las características de las prestaciones. En ambos procesos es fundamental la participación de todas las personas implicadas. En ese sentido, fue muy interesante la experiencia de participación de los colegios profesionales de trabajo social y algunas entidades del tercer sector en la reciente modificación del decreto de las AES. Además, en estos momentos, aumentan las posibilidades de hacer propuestas, pues no estamos atados de pies y manos, como ocurría entonces, debido a que el decreto de la RGI y la propia Ley eran inamovibles.

Para casi terminar, debo decir que, en mi opinión, el espíritu perdido de las AES sería adecuado hoy en día si el Sistema se revisara de arriba abajo, es decir, si tuviéramos un sistema de prestaciones único: la verdadera ventanilla única, no el mirador antes mentado. Bajo mi punto de vista, tendría bastante más sentido, en lo que a la atención a las personas y la propia gestión se refiere, una gestión combinada que partiera de los servicios sociales de base -en consideración a su mayor proximidad a las personas que precisan nuestra atención-y culminara con Lanbide como entidad que resolviera y abonara las prestaciones. Realmente no invento la pólvora: se trataría de volver a una gestión con grandes similitudes con la anterior, en la que la resolución de los expedientes estuviera unificada.

Si todas las partes implicadas accedieran, además, a una única aplicación informática (voy camino del anatema por escribir eso), la tramitación se simplificaría sustancialmente. Y si la misma aplicación sirviera de base para la gestión, por una parte, de la RGI y, por otra, de las AES, ni que decir tiene que agilizaríamos el trabajo de todas las partes implicadas mucho más. Nunca he entendido por qué hay tal afición a tener aplicaciones propias para cada entidad: implican muchísimo más gasto, más dificultades para planificar, más problemas para unificar información de cada persona... Hace unos años todavía cabía alguna explicación sensata, pero que hoy en día sigamos igual -quizás peor, ahora interoperabilizándonos-, me parece un despropósito.

Es evidente que una propuesta de estas características precisaría un estudio de considerable profundidad (desde las necesidades de personal hasta los matices más pequeños de la gestión), amén de sosiego - para que las partes implicadas no se enrocaran en sus posiciones antes de iniciar la meditación-y la menor prisa posible, pues la planificación requeriría detalles dignos del encaje de bolillos. 
Quienes trabajen en el Sistema, ¡no escapen!, pues ese punto de vista no tiene demasiadas amistades (dos o tres personas más, osadas locas ellas) y les garantizo el fracaso de mi propuesta, en la presente revisión, al menos. No obstante, inasequible al desaliento, defenderé donde haga falta que es posible, beneficioso para las personas atendidas $y$, aunque casi nadie me crea, también para las personas profesionales que participan en todos los ámbitos de la Administración (una vez pasados los nervios iniciales, por supuesto). La gran pega es que todas las partes deberíamos estar dispuestas a cambiar, y eso gusta tan poco...

\section{Incidencias de la gestión}

Anoche inventé un placer nuevo, y me disponía a gustarlo por primera vez cuando un ángel y un demonio llegaron presurosos a mi casa. Ambos se encontraron delante de mi puerta y se pusieron a discutir sobre mi placer recién creado. Uno gritaba: ‘jes un pecado!’. Y el otro decía en igual tono: "ies una virtud!

GIBRÁN JALIL GIBRÁN (1988)

Cualquier persona interesada que analice los informes críticos con la gestión de Lanbide tendrá claros los problemas que se repiten. Si hablara con quienes en Lanbide se dedican a la gestión de la RGI, podría añadir a su conocimiento otros puntos de vista respecto a tales problemas. Ambos puntos de vista son imprescindibles para entender la casuística en toda su complejidad.

Tanto para la revisión de la Ley como, sobre todo, para la decisión del contenido de los decretos que la desarrollarán, será preciso que se analicen todos estos asuntos uno a uno, pues la mayoría de problemas tendrán orígenes múltiples. Utilizaré un par de ejemplos para intentar explicar esta cuestión: el primero es muy conocido y el segundo - a pesar de sus graves consecuencias- no goza de tanto reconocimiento.

\section{a. Suspensiones de la renta de garantía de ingresos}

El contenido del artículo 26 de la Ley 18/2008 es muy general y, a pesar de que el artículo 43 del Decreto 147/2010 le añade algunas especificaciones, siguen quedando en el tintero algunos aspectos de interpretación dudosa. En general, la suspensión se produce cuando deja de cumplirse algún requisito $y$, en ocasiones, se ha denunciado la falta de proporcionalidad a la hora de decidir imponerla; por ejemplo, no acudir a una cita para revisar la solicitud de empleo implica suspensión (de un mes), y también la implica salir de la CAE sin avisar (un mes o extinción, dependiendo del tiempo), o rechazar una oferta de empleo (un año).

Las consecuencias que generan esas tres situaciones son absolutamente diferentes: la primera puede entenderse como un despiste; la segunda resulta sospechosa (por una parte, por haberse ido sin avisar, y por otra, por los gastos precisos para el traslado); y la tercera es muy grave, salvo que exista una verdadera razón que la justifique.

La normativa, acaso, agradecería un listado de posibles situaciones admisibles, con el fin de que no hubiera dudas respecto a las implicaciones de incumplir cada requisito; no obstante, recoger toda la casuística resulta absolutamente imposible. Las situaciones relacionadas con el empleo, a buen seguro, son las que suponen mayores complicaciones: a pesar de que la normativa haga referencia a "un empleo adecuado de acuerdo con la legislación vigente" ${ }^{11}$, no siempre habrá acuerdo respecto a lo que implica el apelativo "adecuado”, en particular, porque el mismo empleo puede resultar adecuado para una persona y totalmente inadecuado para otra.

De la misma forma, el mero olvido también puede resultar complicado. ¿Hasta dónde debemos llegar en cuanto a la flexibilidad en lo relativo al cumplimiento de trámites (citas, comunicación a Lanbide de cambios en la UC o viajes a realizar)? ¿Cuántas veces debe recordar la Administración los requisitos a las personas beneficiarias? ¿Debería Lanbide organizar un sistema de aviso, como si se tratara del servicio BetiOn? ¿Dónde está el límite de la responsabilidad de cada cual?

\section{b. Necesidad de tener en cuenta situaciones económicas especiales}

La normativa reguladora del Sistema especifica con detalle los ingresos económicos a computar y los que no se tendrán en cuenta. Por lo que se refiere a los gastos, en cambio, ofrece escasas oportunidades de deducción: impuesto sobre la renta, Seguridad Social y sentencias judiciales.

Así, puede ocurrir que una familia con unos ingresos teóricamente suficientes se encuentre en una situación económica apurada de verdad si ha de hacer frente a gastos que la normativa no tiene en cuenta. El ejemplo más claro es el de las personas en situación de discapacidad o dependencia, aunque tal situación aún no sea oficial. En general, todas esas personas han de afrontar gastos elevados, básicamente, para disponer de ayuda en su hogar y, en función del caso, para pagar otro tipo de necesidades (sillas de ruedas, camas especiales, tratamientos).

${ }^{11}$ Ley 4/2011, artículo décimo, que da nueva redacción al apartado 2.b del artículo 19:

Esta disponibilidad incorporará también el compromiso de permanecer inscritas ininterrumpidamente como demandantes de empleo, de no rechazar un empleo adecuado de acuerdo a la legislación vigente, de no darse de baja voluntaria ni definitiva ni temporal del empleo y de no acogerse a una situación de excedencia laboral sin causa extrema justificada. 
Tal y como señalaba al indicar la subsidiariedad del Sistema, debemos asumir que este Sistema no puede hacer frente a todas las necesidades de estas personas; a pesar de lo cual, entiendo que es posible ofrecer ciertos mínimos, por ejemplo, para conseguir algún complemento mediante la RGI u ofreciendo apoyo para algunos gastos básicos de la vivienda.

Además, desde un punto de vista economicista, teniendo en cuenta todas las responsabilidades de las administraciones, si el objetivo

fundamental es que el mayor número posible de personas puedan residir en su propia casa, en lugar de hacerlo en residencias, el Sistema puede dar un pequeño impulso a tal objetivo.

A pesar de que existen múltiples ejemplos, para hacer una reflexión profunda debemos ir a la raíz de todas esas incidencias, sin obviar su poso filosófico, por mucho que para determinadas personas no sea preciso para entender 'los hechos'. La gestión de la RGI siempre ha sido problemática, también las diputaciones forales tenían que hacer frente a múltiples problemas, pues tales no surgieron de repente debajo de un hongo - mediante alguna suerte de sortilegio - cuando la gestión pasó a Lanbide. Dicha gestión es complicada porque asume muchos aspectos de la vida cotidiana: situaciones familiares, económicas, y el reflejo administrativo de todas ellas; y son todas muy cambiantes. Si, además, las personas son inmigrantes, los problemas se duplican -la documentación de los países de origen, los trámites y, ni que decir tiene, las diferencias culturales que dificultan la mutua comprensión-y, muchas veces, el problema no es el idioma, sino las mentalidades opuestas.

Cuando citaba la 'falacia de la planificación', no he tenido presente otra característica de nuestro contexto, acaso la raíz de muchos de nuestros problemas. En el modelo de gestión anterior, los servicios sociales de base recogían las solicitudes, hacían una primera valoración y, en consecuencia, derivaban el caso a la correspondiente diputación foral con la oportuna propuesta, para que allí se tomara la decisión definitiva. Como resultado del cambio en la gestión, una única entidad se ocupa de todo (tras una muy breve formación previa), y desaparece la participación de los servicios sociales. En muchos expedientes, tal cambio no implica problema alguno, pues la situación es clara y no requiere interpretación. En otros, por el contrario, el caso no cumple a rajatabla las indicaciones de la normativa y, por tanto, quien se ocupe de la gestión tiene dos opciones: interpretar lo que no resulte evidente (y para eso, además de la actitud adecuada, es preciso un conocimiento profundo), basándose para ello en las líneas fundamentales de la normativa; o denegar lo que no esté meridianamente claro, porque la normativa no lo especifica. En esa coyuntura, algunas situaciones se repiten a menudo, y quienes gestionan, poco a poco, van acumulando interpretaciones hasta que, finalmente, establecen un buen número de criterios, porque no es factible quedarse esperando a la modificación de la normativa.

Hasta ahora así hemos avanzado, en el filo de la normativa. ¿Cuál es el enredo añadido? Que en esa labor de interpretación no se ha considerado el punto de vista de los servicios sociales. Tal situación, en sí misma, no supondría mayor problema si nuestra normativa fuera mucho más estricta, es decir, del estilo de la que regula las prestaciones de desempleo. La nuestra, por el contrario, abre caminos a las excepciones y a las interpretaciones en el sentido más amplio de la palabra; en todo caso, es preciso conocerla en profundidad para poder utilizar determinados resquicios.

Cuando se decidió el cambio en el Sistema, se ignoró en gran medida la experiencia anterior, de forma que se perdió la experiencia acumulada -básicamente relativa a la interpretación de la casuística- en ayuntamientos, diputaciones y en el propio Gobierno Vasco. Por otra parte, las personas que han asumido la responsabilidad de la gestión actual, empezando de cero, han hecho lo que buenamente han podido, y bajo presión, con toda la triste ayuda que esa situación ofrece. En esa tesitura, los desacuerdos estaban garantizados: quien tenía conocimiento no entendía qué se estaba decidiendo; quienes gestionan ahora no podían entender que se criticara su trabajo cuando estaban interpretando estrictamente la normativa; quienes estábamos en el medio no entendíamos nada...

Las cosas han cambiado sensiblemente. A pesar de ello, el ambiente no es el mejor que podríamos tener, pues ahora disponemos de dos tipos de conocimiento: por una parte, el tradicional, es decir, aquel en cuyas interpretaciones se adivina el toque de los servicios sociales; por otra parte, el nuevo conocimiento, correspondiente a quienes se han dedicado a la gestión desde 2011 hasta nuestros días, en cuyas interpretaciones tiene mayor peso el ámbito jurídico. Una vez más, estamos obligados a buscar el equilibrio. En el proceso de revisión de la normativa habrá ocasión de considerar todos los puntos de vista. Sin embargo, será necesario que cada cual, además de entender 'los hechos' desde su propia perspectiva, sea capaz de tratar de entender los de enfrente en igual medida.

En mi propia experiencia (espero que se me perdone la presunción, pero creo que pocas personas han soltado más maldiciones que yo, tanto en público como en privado), para conseguir algún resultado que merezca la pena, es imprescindible evolucionar en cierto sentido: cuando nos preguntamos cómo es posible que otra persona haya soltado tamaña burrada, debemos conseguir -tras el oportuno salto mortal- preguntarle $-y$ sin enfadarnos, he ahí la última pirueta- por qué piensa lo que piensa. Nos esperan sorpresas sin cuento, pues muchas veces estaremos de acuerdo en cuestiones básicas. Pero eso no es nada fácil, y no siempre se consigue: unas 
veces porque realmente no se desea; otras veces se consigue entre determinadas personas, sin éxito general; y en el resto de casos, la burrada realmente era una barbaridad.

\section{Coordinación, fraude y otros temas delicados}

Es ridículo no intentar evitar tu propia maldad, lo cual es posible, $y$, en cambio, intentar evitar la de los demás, lo cual es imposible.

Marco Aurelio (1983)

Aunque la coordinación entre sistemas requiera un artículo propio, señalaré algunas pinceladas básicas, y la primera es una obviedad: la firma de convenios entre administraciones no es sinónimo de coordinación. Es imprescindible que exista una intención verdadera y, para conseguir eso, todas las personas implicadas deben entender de igual modo la necesidad, y los procedimientos han de ser muy claros.

Entre quienes trabajan en el Sistema, hay personas de todo tipo y condición, en el continuum que podemos formar desde la santidad hasta quien se asemeje al señor Bartleby, descrito por Melville (2015) -que siempre decía "preferiría no hacerlo"-; y para organizar el trabajo de todas ellas, acaso, el primer paso debería ser establecer si todos los casos requieren la atención coordinada de todos los ámbitos del Sistema.

A lo largo de los últimos años, se ha hablado en múltiples ocasiones de las personas perceptoras de pensiones, pues no tiene sentido que acudan a Lanbide a cumplir con los trámites que sean precisos; y ya existen propuestas para automatizar por otras vías la gestión en esos casos. Por otra parte, también se han mencionado las personas en situación muy complicada, pues en determinados supuestos los servicios de Lanbide no serán adecuados para ellas; aunque creo que no hemos profundizado lo suficiente en esa línea.

En todo caso, creo que en determinados supuestos es imprescindible la relación directa entre los servicios sociales de base y Lanbide, sobre todo si se consigue establecer el contacto antes de que la gestión de la RGI tenga consecuencias graves. En estos últimos años, los casos de suspensión antes citados han sido un ejemplo evidente. Además de revisar en la normativa los aspectos generales relacionados con las suspensiones, pienso que convendría establecer un procedimiento previo al momento en que la suspensión se haga efectiva, al menos para determinados tipos de casos: cuando haya menores a cargo, o personas de edad avanzada $u$ otras con problemas de salud en la unidad de convivencia. Los dos primeros tipos son sencillos de detectar a partir de la edad de las personas que componen la UC; las cuestiones relacionadas con la salud, por el contrario, requieren que los servicios sociales hayan aportado la información pertinente con anterioridad.

No obstante, el verdadero problema no es organizar la coordinación, sino decidir qué se hará en tales casos, pues por mucho que tengan más problemas, dichas personas deberían cumplir los requisitos, como todo el mundo. Intento explicarlo con un ejemplo, más común de lo que parece. Una familia es beneficiaria de RGI y PCV. Etxebide les ofrece un alquiler social y la familia lo rechaza. El argumento utilizado es que la hija tiene problemas de salud y que la casa ofrecida no es adecuada para ella. Etxebide no acepta tal argumento, pues la casa está en las debidas condiciones y, como consecuencia, Lanbide les quita la PCV. Acuden entonces al Ayuntamiento para solicitar AES por alquiler. En ese servicio también entienden que el motivo del rechazo carecía de fundamento, pero por otra parte, consideran que la familia no podrá salir adelante sin prestaciones, sobre todo conviviendo con menores y con la abuela.

El hecho de que dos servicios del mismo Sistema tomen decisiones contrarias no es la mayor complicación, sino qué hacer en tales casos, cuando sabemos que la responsabilidad es de la pareja y no de quienes están a su cargo, quienes pagarán las consecuencias de igual manera. El punto de vista flexible, teniendo en cuenta la situación de las personas inocentes, propondrá la concesión de alguna prestación, bien sea a través de una interpretación generosa de la normativa, bien gracias al presupuesto añadido por el Ayuntamiento, con el fin de no tener dudas respecto al cumplimiento de la norma. El punto de vista estricto denegará la propuesta, y la última oportunidad para esa familia será percibir ayudas de alguna entidad (quizás, de un presupuesto que provenga de la propia Administración, por liar un poco más el ejemplo).

En mi opinión, la actitud de la persona que atiende el caso estará íntimamente relacionada con su experiencia previa y con la relación que tenga con las personas a las que atiende. Por una parte, no es lo mismo conocer directamente las vicisitudes de la familia que limitarse a analizar la documentación. Por otra, es muy diferente atender a una persona sentada enfrente que analizar expedientes sin ver a las personas implicadas. Del mismo modo, nada que ver tendrá nuestra interpretación si es la primera vez que la persona toma una decisión de ese estilo, o si las repite una y otra vez; por ejemplo, si rechazara la próxima propuesta de Etxebide o el siguiente mes perdiera voluntariamente la ocasión de acceder a un empleo.

Es evidente que, en ocasiones, se rechazan las viviendas de protección oficial porque aceptarlas implica asumir gastos (conexión a servicios, muebles, electrodomésticos). Supongamos que la revisión normativa tiene en cuenta ese tipo de casos y que, a pesar de todo, alguien rechaza una vivienda porque la que actualmente ocupa está en el centro 
y la que le ofrecen, a su juicio, está muy lejos, en un barrio nuevo (eso también es un ejemplo real). En ese supuesto, ¿qué podríamos hacer con esa familia?

Ese tipo de supuestos $-\mathrm{y}$ otros de dificultad interpretativa similar que no podamos preverrequerirán atención específica, que podría ofrecerse mediante algún tipo de comisión técnica constituida a tal efecto, la cual tuviera en cuenta los dos tipos de conocimiento citados más arriba. El estudio de la casuística más complicada o peculiar supondría, gracias a sucesivos análisis ad hoc, una acumulación de conocimiento beneficiosa para todas las personas atendidas y para el conjunto del Sistema.

Esas cuestiones están íntimamente relacionadas con mi convencimiento respecto a las bondades de la participación de los servicios sociales de base en la gestión de las prestaciones del Sistema, siempre que sigamos considerando preciso garantizar el famoso doble derecho: por una parte, a disponer de medios económicos para hacer frente a las necesidades básicas de la vida y, por otra, a contar con apoyo personalizado para la inclusión laboral y social.

Tal y como he intentado explicar desde variadas perspectivas, la revisión de la normativa -0 de la gestión - no lo arreglará todo. El viejo Marco Aurelio agradecía a su padre contar con algunas aptitudes y, entre ellas, es probable que agradeciéramos también la siguiente: "la previsión desde lejos y la regulación previa de los detalles más insignificantes sin escenas trágicas”.

En nuestro ámbito, el final de la frase tiene su aquel, pues gustamos de utilizar los problemas como carnaza (puede que también lo hagan en otros ámbitos o lugares, será que he viajado poco). Debido a esa tendencia, los temas se han mezclado en muchas ocasiones, y las consecuencias negativas debidas a la gestión se han vendido como casos de fraude; por otra parte, algunos grupos han negado la existencia del fraude, como si las gentes tramposas fueran de otro planeta. Es probable que tanto un grupo como el otro consideren que están proclamando la verdad, pero, a mi juicio, ambos grupos defienden puntos de vista parciales.

En un breve esquema podemos recoger todo tipo de personas beneficiarias del Sistema:

1. Quienes están en situación precaria y cumplen los requisitos de la normativa para beneficiarse de las prestaciones.

2. Quienes también están en tal situación, pero no cumplen alguno (o muchos) de los requisitos. No perciben nada.

3. Casos del segundo grupo, pero que han decidido ingeniárselas de alguna manera para conseguir el derecho. El ejemplo típico sería utilizar documentación falsa.

4. Quienes tienen suficiente para vivir, pero han decidido mentir de alguna manera para percibir prestaciones. Un ejemplo habitual sería una pareja con menores a cargo: el padre no consta en el padrón y se considera unidad monoparental.

5. Personas que han decidido vivir sin trabajar, 0 haciendo lo mínimo imprescindible, pues con las prestaciones se arreglan perfectamente.

6. Personas que no pueden trabajar (con problemas físicos o mentales) y que están en una situación muy grave, pero no tienen relación con el Sistema.

Es probable que me haya dejado algo, pero creo que la mayoría de supuestos podrían recogerse en esos grupos. Si nos dedicamos a alguna actividad relacionada con la gestión de prestaciones económicas, es más que probable que seamos capaces de ubicar algunos nombres propios en cada apartado. Por otra parte, si nos pidieran establecer el porcentaje de casos que supondría cada uno, en función de nuestro punto de vista, marcaríamos porcentajes muy dispares.

Si dispusiéramos de la renta básica ${ }^{12}$, esa circunstancia carecería de importancia, pero en nuestra realidad la tiene, sobre todo porque la sospecha de fraude incide particularmente en el colectivo inmigrante, como si el fraude fuera un invento de quienes vienen de fuera y las gentes autóctonas, además de ser de aquí de toda la vida de Dios, fuéramos limpias y puras. Así, ese esquema precisaría dos columnas al lado, para marcar a las personas en función de su presunta bondad o maldad, pues de todo hay en todas partes, si se me permite la obviedad.

¿Cuál es la diferencia? Si pilláramos a la pareja citada como ejemplo en el cuarto apartado, podríamos pensar cualquier cosa, pero difícilmente extenderíamos la sospecha a todas las familias monoparentales. En cambio, si se tratara de uno de los fraudes citados en el tercer ejemplo, y hubiera sido cometido por una persona inmigrante, lo utilizaríamos como ejemplo de actitud de todo el colectivo.

He utilizado esos ejemplos porque, al reflexionar respecto a la normativa, el camino más directo es utilizar la casuística. En nuestro día a día, los casos sospechosos de fraude $-y$ las personas con mucha cara- generan mucho más trabajo (incluyendo alguna situación de miedo) que los casos más complicados de analizar; no obstante, el problema no es el trabajo en sí, sino el ambiente suspicaz que generan.

Los quebraderos de cabeza de quienes se ocupan de la gestión no se centrarán en los cuarenta casos 'normales' - por peliaguda que sea la situación-

${ }^{12}$ La renta básica implica que todas las personas tengan derecho a percibirla. Otra cuestión será dilucidar si eso es mejor para todo el mundo, pues las cuantías que se plantean suelen ser inferiores a las que se conceden mediante nuestro Sistema. Pero ésa es otra discusión. 
que han podido atender; lo harán en quienes hayan estado enredando, o en quienes reivindican todo tipo de derechos sin intención de asumir responsabilidad alguna. El dicho que afirma que pagan justos por pecadores no es ninguna bobada.

En algunos sectores se considera que las personas que andan metidas en líos y en trampas lo hacen para vivir del cuento, gracias a la Administración o, mejor dicho, al dinero del conjunto de la sociedad. De todas formas, aunque admitamos que existen ese tipo de personas, tengo claro que, en muchas ocasiones, lo hacen porque no tienen suficiente para vivir -ni trabajo, ni oportunidades, ni esperanza-, y aprovecharán cualquier oportunidad para sacar los pies del barro, tal y como cualquiera haría si se encontrara en sus circunstancias.

Resulta harto complicado ubicar a cada persona en el grupo que le corresponde - mucha cara o mucha necesidad (o una mezcla de ambos) $-y$, lamentablemente, es muy sencillo equiparar esos dos grupos, para lo bueno y para lo malo. En ese camino, cometeremos múltiples errores, pero, acaso, consigamos que quienes están en el segundo grupo no pasen al primero, por mucho que no sea su voluntad, porque el Sistema, el resto de servicios, o la propia sociedad, no les ofrezca esperanza alguna.
Quienes trabajamos en este ámbito tenemos la oportunidad de dar nuestra opinión; cuestión distinta será lo que las personas que ocupan puestos de responsabilidad, el Parlamento o los medios de comunicación hagan con ella. Muchas personas gustan de arreglar el mundo tomando café, pero fuera de ese contexto no dicen gran cosa; consideran que carece de sentido, porque tienen claro que supone perder sus energías en vano.

Para todas ellas, y para quienquiera, Jon Sarasua (2010) nos regaló una historia muy adecuada. En realidad, se trata de una historia que alguien le contó en Brasil, la de la beija-flor. Se trata del colibrí, el pájaro más pequeño de Brasil, y ésta es la historia, pequeña, igual que el pajarito:

En cierta ocasión, la selva ardió. Todos los animales escaparon a toda prisa, dejándolo todo. La beija-flor también, pero tomó agua del río en el pico y regresó, al parecer, a echar una gota al fuego. Después otra vez, y otra más. Le dijeron que era en vano, que así no conseguiría apagar el fuego. Respondió que ya lo sabía, pero que eso era lo poco que ella podía hacer. 
BAUMAN, Z. (2017): Retrotopía, serie Estado y Sociedad, Barcelona, Paidós.

- (2009): Ética posmoderna, Madrid, Siglo XXI.

DEPARTAMENTO DE MEDIO AMBIENTE, PLANIFICACIÓN TERRITORIAL Y VIVIENDA (2017): “Orden del Consejero de Medio Ambiente, Planificación Territorial y Vivienda, por la que se inicia el procedimiento de elaboración del proyecto de Decreto sobre el Derecho Subjetivo de Acceso a la Ocupación Legal de una Vivienda Digna y Adecuada", Vitoria-Gasteiz, Gobierno Vasco [khttp://www.legegunea.euskadi.eus/ x59-contfich/es/contenidos/tramita_decreto/ dncg_dec_135117_17_05/es_def/index.shtml ].

GEORGE, S. (2004): Otro mundo es posible si..., serie Encuentro, Barcelona, Icaria; Intermon Oxfam.

GIBRÁN JALIL GIBRÁN (1988): El profeta. El loco. El vagabundo, Madrid, Akal.

HUXLEY, A. (2009): La isla, serie Pocket, Barcelona, Edhasa.

KAHNEMAN, D. (2014): Pensar rápido, pensar despacio, Barcelona, Debolsillo.

MARCO AURELIO (1983): Meditaciones, Madrid, Gredos.

MELVILLE, H. (2015): Bartleby, el escribiente, Madrid, Nórdica Libros.

PAÍS VASCO (2017): “Decreto 16/2017, de 17 de enero, de modificación del Decreto de ayudas de emergencia social", Boletín Oficial del País Vasco, no 16, 24-1-17 [<https:// www.euskadi.eus/y22-bopv/es/bopv2/ datos/2017/01/1700417a.shtmls].

- (2017): “Ley 2/2017, por la que se aprueban los Presupuestos Generales de la Comunidad Autónoma de Euskadi para el ejercicio 2017", Boletín Oficial del País Vasco, nํ74, 19-4-17 [rhttps://www.euskadi.eus/y22-bopv/es/ bopv2/datos/2017/04/1701927a.shtml〉].

- (2011): “Decreto 4/2011, de 18 de enero, de las Ayudas de Emergencia Social”, Boletín Oficial del País Vasco, no 27, 9-2-11 [shttps://www.euskadi.eus/ y22-bopv/es/bopv2/datos/2011/02/1100673a. shtml>].

- (2011): “Ley 4/2011, de 24 de noviembre, de modificación de la Ley para la Garantía de Ingresos y para la Inclusión Social", Boletín Oficial del País Vasco, ํㅜ 233, 12-12-11 [rhttps:// www.euskadi.eus/r47-bopvapps/es/bopv2/ datos/2011/12/1105924a.shtml ].

- (2010): "Decreto 147/2010, de 25 de mayo, de la Renta de Garantía de Ingresos", Boletín Oficial del País Vasco, no 114, 17-6-10 [rhttps:// www.euskadi.eus/y22-bopv/es/bopv2/ datos/2010/06/1003020a.shtml>].

- (2008): “Ley 18/2008, de 23 de diciembre, para la Garantía de Ingresos y para la Inclusión Social”, Boletín Oficial del País Vasco, n- 250, 31-12-08 [rhttps://www.euskadi.eus/r47-bopvvaci/es/ bopv2/datos/2008/12/0807235a.shtml/].

- (2001): “Orden de 14 de febrero de 2001, del Consejero de Justicia, Trabajo y Seguridad Social, por la que se establecen los estímulos al empleo de las personas titulares de la Renta Básica y de las personas beneficiarias de las Ayudas de Emergencia Social", Boletín Oficial del País Vasco, nº 37, 21-2-01 [rhttps:// www.euskadi.eus/y22-bopv/es/bopv2/ datos/2001/02/0100962a.shtml'].

PARLAMENTO VASCO (2017): “Proposición no de Ley $12 / 2017$, relativa a medidas de reforma de los criterios de admisión en el registro del Servicio Vasco de Vivienda-Etxebide 
(Acuerdo del Pleno)", Boletín Oficial del Parlamento Vasco, XI legislatura, $\mathrm{n}-15$, 17-2-17, págs. 1.295-1.296 [<http://www. legebiltzarra.eus/sm_abopvc/DDW?W=boc_ clave $=\% 27111102010049201702170012$ 95\%27〉].

- (2016): “Proposición no de Ley 32/2016, en relación con el desarrollo reglamentario del derecho subjetivo de acceso a la ocupación legal de una vivienda digna y adecuada y de la nueva prestación económica de vivienda (Acuerdo del Pleno)", Boletín Oficial del Parlamento Vasco, X legislatura, no 169, 22-4-16, pág. 33.047 [<http://www. legebiltzarra.eus/sm_abopvc/DDW?W=boc_ clave $=\% 27101102010909201604220330$ $49 \% 27>$.
- (2015): “Proposición no de Ley 23/2015, en relación con la adecuación del decreto regulador de las AES (Acuerdo del Pleno)", Boletín Oficial del Parlamento Vasco, X legislatura, nำ117, 13-3-15, pág. 22.169 [ [http://www. legebiltzarra.eus/sm_abopvc/DDW?W=boc_ clave $=\% 27101102010693201503130221$ $69 \% 27>$.

SARASUA, J. (2010): Ertzeko zatiak, Lasarte-Oria, Argia.

SARRIONANDIA, J. (1997): Hitzen ondoeza, Tafalla, Txalaparta.

URIBE, K. (2016): Elkarrekin esnatzeko ordua, serie Narratiba, Zarautz, Susa. 
